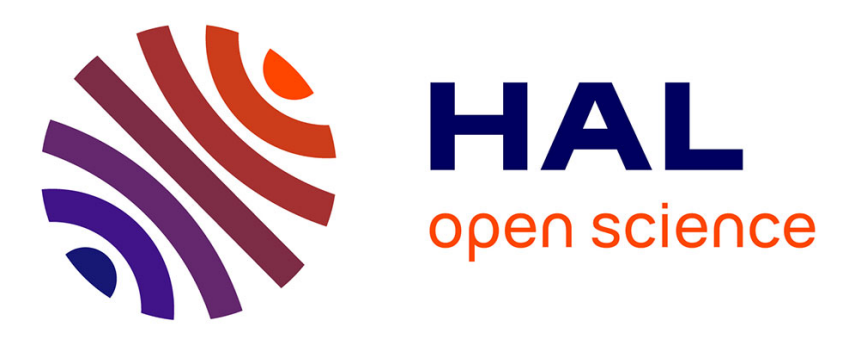

\title{
Access to antiretroviral drugs and AIDS management in Senegal
}

\author{
Alice Desclaux, Mounerou Ciss, Bernard Taverne, Papa Salif Sow, Marc \\ Egrot, Mame Awa Faye, Lanièce Isabelle, Omar Sylla, Eric Delaporte, \\ Ibrahima Ndoye
}

\section{To cite this version:}

Alice Desclaux, Mounerou Ciss, Bernard Taverne, Papa Salif Sow, Marc Egrot, et al.. Access to antiretroviral drugs and AIDS management in Senegal. AIDS, 2003, Suppl 3, 17, pp.S95-S101. ird02068755

\section{HAL Id: ird-02068755 https://hal.ird.fr/ird-02068755}

Submitted on 25 Mar 2019

HAL is a multi-disciplinary open access archive for the deposit and dissemination of scientific research documents, whether they are published or not. The documents may come from teaching and research institutions in France or abroad, or from public or private research centers.
L'archive ouverte pluridisciplinaire HAL, est destinée au dépôt et à la diffusion de documents scientifiques de niveau recherche, publiés ou non, émanant des établissements d'enseignement et de recherche français ou étrangers, des laboratoires publics ou privés. 


\title{
Access to antiretroviral drugs and AIDS management in Senegal
}

\author{
Alice Desclaux ${ }^{a}$, Mounirou Ciss ${ }^{b}$, Bernard Taverne ${ }^{c}$, Papa S. Sow ${ }^{d}$, Marc Egrot ${ }^{a}$, Mame A. \\ Faye $^{d}$, Isabelle Laniéce ${ }^{e}$, Omar Sylla $^{f}$, Eric Delaporte ${ }^{g}$ and Ibrahima Ndoye ${ }^{f}$
}

\section{Abstract :}

Objectives: Description and analysis of the Senegalese Antiretroviral Drug Access Initiative (ISAARV), the first governmental highly active antiretroviral therapy (HAART) treatment programme in Africa, launched in 1998.

Methods and results: ISAARV was initially an experimental project designed to evaluate the feasibility, efficacy and acceptability of HAART in an African context. It was based on four principles: collective definition of the strategy, with involvement of the health professionals who would be called on to execute the programme; matching the objectives to available means (gradual enrollment according to drug availability); monitoring by several research programmes; and ongoing adaptation of treatment and follow-up according to the latest international recommendations.

Persons qualifying for antiretroviral (ARV) therapy are selected on the basis of immunological and clinical criteria, regardless of economic and social considerations. A system of subsidies was created to favor access to ARV. Following the ARV price reductions that occurred in November $2000,100 \%$ subsidies were created for the poorest participants. Optimal adherence was ensured by monthly follow-up by pharmacists and support groups held by social workers and patient associations. The chosen supply and distribution system allowed drug dispensing to be strictly controlled.

Conclusion: The ISAARV programme demonstrates that HAART can be successfully prescribed in Africa. This experience has served as the basis for the creation of a national treatment programme in Senegal planned to treat 7000 patients by 2006 .

Keywords: Access, Africa, antiretroviral, highly active antiretroviral therapy, HIV, public health, Senegal

\section{Introduction}

In discussions held since 1996 on access to antiretroviral therapy in Africa, it has clearly emerged that provision of drugs alone will not solve the crisis [1].

The principal obstacles so far identified include:

- the lack of health infrastructures required to ensure treatment follow-up;

- high drug costs relative to national health budgets in low-income countries;

From the a) Laboratoire d'Ecologie Humaine et d'Anthropologie, University of Aix-Marseille, France, the b) National Laboratory, Ministry of Health, Dakar, the c) Institut de Recherche pour le Développement (IRD, UR 36), Dakar, the d) Fann University Hospital, Dakar, the e) French Cooperation and National AIDS Program, Dakar, the f) National AIDS Program, Dakar, Senegal and the g) institut de Recherche pour le Développement (IRD, UR 36) and University of Montpellier, France.

Sponsorship: This work was partially supported by a grant of the French National Agency for Research on AIDS (ANRS), by European Union (contract B7-6211/99/005) and by Institut de Recherche pour le Développement (IRD). 
- concerns over adherence to treatment;

- the risk of accentuating inequalities between rich and poor; and

- the emergence of viral resistance.

Several consensus conferences have concluded that these obstacles must not be used as an excuse to delay implementation of life-saving antiretroviral therapy programmes [1]. However, these arguments correspond to real public health challenges, as stated in international expert recommendations [1-6].

When the National Program Against AIDS in Senegal (PNLS) decided in 1998 to launch a pilot project - the Senegalese Initiative for Access to Antiretroviral Drugs (ISAARV) - its strategic choices were determined by the desire to create an infrastructure capable of avoiding these pitfalls. This infrastructure needed to be capable of being integrated into the existing care system and not require major supplementary resources that would threaten its sustainability.

After 3 years of operation, these strategic choices can be debated in the light of results of research programmes [7]. This critical analysis is necessary before extrapolating the pilot project into a national scale programme.

This article describes the organization of ISAARV, including drug access and distribution. The results of the pilot project are interpreted in terms of the above-mentioned public health challenges. Questions concerning adherence and resistance are dealt with in two other articles published in this issue $[8,9]$.

\section{The context of ISAARV}

The seroprevalence of HIV in Senegalese adults remains below $2 \%$, and is not currently increasing. This relatively low prevalence is partly due to early implementation of well-designed national prevention campaigns [10]. Mobilization of health authorities and political decision-makers aimed at facilitating the management of HIV-infected patients in Senegal was accompanied by debates on the use of antiretroviral drugs.

\section{Strategic choices}

The initial strategic choices for the ISAARV programme were prudent, given uncertainties over the feasibility, efficacy and acceptability of antiretroviral therapies, and the material and financial constraints existing at that time. ISAARV was designed as a pilot project linked institutionally to PNLS, under the authority of the Ministry of Health. The project was designed to function integrally within hospital services, with four overriding principles: collective definition of the strategy; objectives in keeping with available means; monitoring through research programmes; and the choice of appropriate treatment and follow-up protocols.

\section{Collective definition of the strategy}

The health professionals who would be responsible for executing the strategic choices (physicians, biologists, virologists, pharmacists and welfare assistants) were invited to participate in the definition and planning of the programme. This choice, necessitated by financial constraints, had two merits: it ensured first that the design of the project took into account existing difficulties, and second that management modalities were adaptable to rapid changes in scientific knowledge, available drugs, and treatment costs. Four committees were created to ensure the institutional organization of the project.

The first committee to be created defines the main orientations of the project and is responsible for control and monitoring; decisions are taken collectively, after discussion among the members. Known as the Eligibility Committee, this committee has overall responsibility for patient recruitment. It counts 15 statutory members (physicians, biologists, pharmacists, persons living with HIV/AIDS, and administrators). 
The Medical Committee defines and periodically revises the medical aspects of the programme (inclusion criteria, therapeutic protocols, clinical follow-up, etc). Monthly meetings are held to examine the medical files of candidates for treatment, and to assess the appropriateness of the therapeutic regimens chosen by clinicians. The committee includes PNLS prescribers and physicians.

The Welfare Committee is responsible for decisions concerning non-medical aspects of the project and provides support measures aimed at optimizing adherence. In particular, it coordinates social surveys of candidates for treatment. It is composed of PNLS health professionals (pharmacists, psychiatrists, etc.) and social workers.

The Drugs and Reagents Management and Supply Committee is charged with managing drug supplies, organizing dispensing sites, and managing relations with private wholesalers.

\section{Matching the objectives with available means}

ISAARV objectives, in terms of the numbers of prescribing and dispensing sites and the number of patients to be treated, were defined in keeping with available means. In 1998, only Dakar, the capital, had an adequate technical infrastructure and sufficient personnel trained in the use of antiretroviral drugs. Three consulting sites were opened (Infectious Diseases Department and Ambulatory Treatment Center of Fann Hospital, and the Internal Medicine Department of the Principal Hospital), with nine prescribing physicians. It was decided that 60 patients could be enrolled in ISAARV with the budget initially available. The number of available treatments increased gradually, following the reduction in drug prices, the launch of clinical trials, and new grants.

[S97]

\section{Monitoring through research programmes}

Several basic and operational research programmes were associated with ISAARV from the outset. These research projects provided a technical accompaniment in virological, bioclinical and social science fields, and their results help in the evaluation of the pilot project.

\section{Choice of treatment and follow-up protocols}

The medical criteria for treatment initiation were chosen on the basis of the 1997 Dakar consensus, as revised in October $2000[2,3]$.

Similarly, protocols chosen to treat children, to prevent mother-child transmission, and for post-exposure prophylaxis, initiated in June and July 2000, were based on international recommendations adapted to African countries (according to the drugs available in Senegal), and were revised in October $2000[2,3]$.

Patients are seen on day 1 , day 7 , day 14 and day 30, and then on a monthly basis. At each visit, the physician writes a prescription and keeps a copy. The drugs are dispensed by a pharmacist, who gives advice on adherence and records the drugs dispensed. The patient gives his/her financial contribution towards the treatment directly to the pharmacist.

Welfare follow-up was intended to include several interviews, but this could no longer be done regularly after the first 180 patients had been enrolled. The welfare interventions consist mainly of monthly group discussion and information sessions held at one of the sites and aimed at optimizing adherence; follow-up social surveys are only done if requested by the patient, the prescriber or the pharmacist.

The strategic choices and organization of ISAARV were efficient for the management of the pilot project. Clinical evaluation after 18 months has shown that the treatment of 58 adult patients was efficient [11]. However, with the increase in the number of patients the limits of the system began to emerge, particularly the timeconsuming nature of the data collection and co-ordination systems. The institutional organization was maintained during the transition from the pilot project to the national programme in 2001, but 'light' patient 
follow-up procedures were implemented, based on monthly visits and data recording. In February 2002, 400 adult patients and 19 children are under highly active antiretroviral therapy (HAART), 17 HIV-positive pregnant women have been included in the (prevention of mother to child transmission (PMTCT) programme and received single dose nevirapine or short course zidovudine according to timing, nine health professionals had a post-exposure prophylaxis.

\section{Access to antiretroviral drugs}

ISAARV was designed to be accessible to all persons requiring treatment with antiretroviral drugs, whatever their nationality or socio-economic status, provided they were resident in Senegal. Residence was preferred over nationality, which has inherent political implications. This ensured optimal medical follow-up, and avoided attracting patients from neighboring countries. In 1998 it was decided to accept the principle of patients' financial participation, the amount paid being calculated according to individual resources.

\section{Access modalities}

Patients selected by a physician on the basis of immunovirologic and clinical criteria (see above) under-went an 'inclusion' social survey by a social worker, with the aims of assessing the patient's economic resources and social support network, identifying other HIV-infected persons in the domestic group, and checking that the patient had correctly understood the constraints of three-drug regimens. The results of the survey were discussed by the Eligibility Committee, which endorsed the decision to treat and determined the patient's financial participation from a table. This procedure was applied throughout the pilot project (1998-2001). Children, health personnel, and active members of people living with HIV/AIDS (PLWA) self-help groups were exempted from financial participation.

The patients' contributions to the cost of their treatment evolved according to the prices imposed by pharmaceu-tical firms [12]. Prices were reduced after November 2000, and a government subsidy of $100 \%$ was introduced.

During the first period (August 1998 to October 2000), patients were required to be able to pay a minimal monthly sum of 21000 FCFA ( 1 US\$ $=640$ FCFA; 1000 FCFA $=1.56$ US\$) in order to be enrolled in the project (Table 1). To avoid raising false hopes, clinicians generally conducted an informal selection, prior to the social survey, on the basis of their patients' presumed ability to pay.

In November 2000 the reduction in prices of antiretroviral drugs was immediately translated into a four-fold reduction in patients' financial participation. The following year, $44 \%$ of newly enrolled patients received a grant covering $100 \%$ of the drug costs (Table 2 ).

The income-based calculation of patients' financial contributions was impractical, mainly owing to the difficulty of assessing an individual's available resources. In addition, the social surveys were lengthy, difficult to conduct, and imprecise. They came up against the pitfalls already known to economists working in Africa when determining the income of a person or a domestic group, as most of them have no declared salary and hold precarious and casual jobs.

During the first 9 months of treatment, the estimated mean direct medical costs paid for by the patient, including [S98] costs of medical visits, biological and radiological examinations, hospitalizations, travel and medicines but excluding the purchase of antiretroviral drugs, were $5200 \mathrm{FCFA} /$ month, a sum representing nearly $15 \%$ of the minimum wage in Senegal [13]. This sum was far beyond the capacities of the bulk of the Senegalese population: in Dakar, a relatively well-off region compared with the rest of the country, $60 \%$ of the population have no permanent job or regular income, nearly $60 \%$ of households live below the poverty threshold, and $83 \%$ of the population have no welfare protection [14]. Thus, the pilot project quantified the weaknesses of an antiretroviral access programme based on patients' financial contribution towards the cost of their treatment and provided an estimate of the amount needed to support patient access to antiretroviral therapy in addition to the cost of drugs. 
Table 1: Changes in tariffs prevailing in the Initiative during its first 3 years (FCFA).

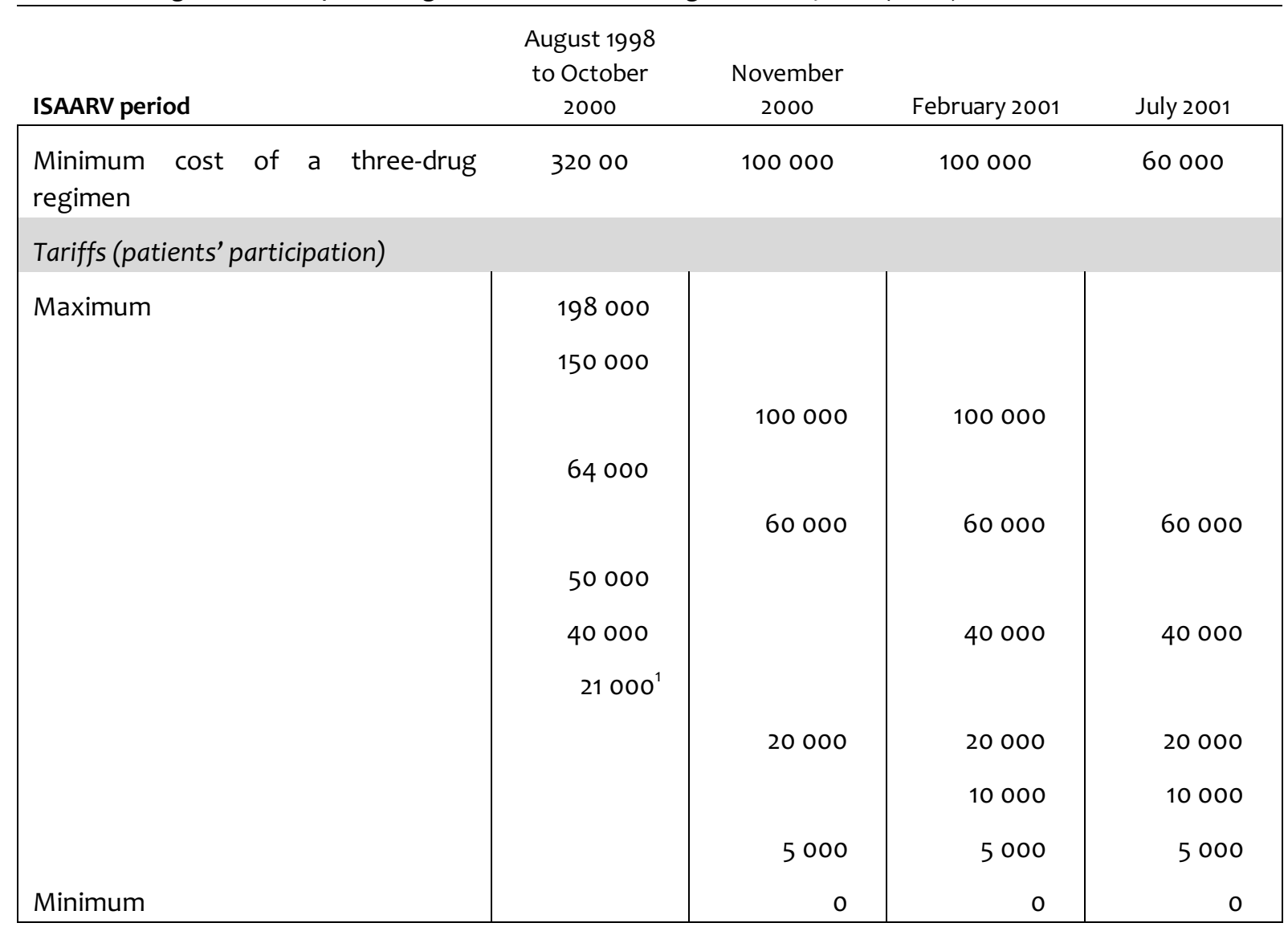

${ }^{1}$ Free access was granted to children, health professionals and active members of PLWA self-help groups. 1 US\$ = 640 FCFA; 1000 FCFA $=1.56$ US\$. ISAARV, Senegalese Antiretroviral Drug Access Initiative.

Table 2: Changes in patients' financial participation at day 1 following the fall in drug prices (FCFA).

\begin{tabular}{llcc}
\hline ISAARV period & \multicolumn{1}{c}{$\begin{array}{c}\text { August 1998 } \\
\text { to October 2000 }\end{array}$} & $\begin{array}{c}\text { November } 2000 \\
\text { to November 2001 }\end{array}$ \\
\hline Participation at day 1 & Médian & 21000 \\
\cline { 2 - 4 } & Mean & 27800 & \\
\cline { 2 - 4 } & Maximum & 198000 & $64(44 \%)$ \\
\hline Number of patients receiving a 100\% grant at day 1 & $10(11,5 \%)$ & 146 \\
\hline Number of enrollments (excluding clinical trials) & 87 & 6 \\
\hline
\end{tabular}

ISAARV, Senegalese Antiretroviral Drug Access Initiative.

\section{Drug distribution}

\section{Context}

Before and during the first period of the ISAARV project, antiretroviral drugs were available in Dakar from three wholesalers and a few private pharmacies, which supplied between 20 and 30 wealthy persons at a monthly cost sometimes exceeding 300000 FCFA. Some of these patients could not be enrolled in ISAARV owing to their place of residence, whereas others preferred the perceived anonymity of this type of access. 
After November 2000, in order to ensure that all patients benefited from the lower drug prices, an agreement was reached between PNLS and wholesalers, whereby the latter could obtain antiretroviral drugs at reduced rates from Fann Hospital pharmacy. The wholesalers thus became secondary dispensing sites (while sales of antiretroviral drugs were forbidden in pharmacies) but, in January 2002, only a dozen patients continued to use them.

\section{Organization}

In Senegal, drugs for the public and semi-public sectors are supplied by the National Supply Pharmacy (PNA). Antiretroviral drugs are delivered to and stored at the Supply Pharmacy, and are dispensed according to the needs of Fann Hospital pharmacy, which was the only [S98] antiretroviral dispensing site for the ISAARV project until January 2001.

In February 2001 a second site was opened at the Social Hygiene Institute (IHS), and secondary sites were chosen as the different components of the ISAARV programme were launched (management of children treatment and mother-to-child prevention).

Fann pharmacy continues to control the distribution of antiretroviral drugs to dispensing sites, including whole-salers. This has the advantage of permitting strict monitoring of stocks and their distribution. However, the increase in drug throughput and in the number of dispensing sites planned to take place when the programme is extended will probably create a major increase in workload in this service that has no mandate to do so.

\section{Available drugs}

In 1998, the ISAARV programme started with five drugs (zidovudine, lamivudine, stavudine, didanosine and indinavir). In early 2002, eight drugs were available, with nine different preparations and a total of 23 different combinations (including 20 three-drug regimens).

\section{The informal drug market}

In Senegal, as elsewhere in Africa, the sale of drugs, including the most recent, also occurs through an informal market, developed by street vendors and shopkeepers [15-17]. It was thus to be expected that antiretroviral drugs would be sold through this channel, although their supply was legally restricted to hospital pharmacies designated by PNLS or to wholesalers, and necessitated medical prescription by selected doctors.

The supply of antiretroviral drugs through the informal market gradually diversified, and prices fell in similar proportions to the ISAARV programme. Injectable Retrovir ${ }^{\circledR}$, sold for 125000 FCFA per box, was the first product to be identified on the informal market, in early 2000 . The same year Retrovir ${ }^{\circledR}$ capsules, Videx ${ }^{\circledR}$, and Zerit $40^{\circledR}$ also became available. The latter was offered for 120000 FCFA per box in July 2000 and only 12000 FCFA in January 2002. In early 2002, 12 drugs had been identified, comprising 13 proprietary preparations and including three preparations at two different dose strengths (Epivir ${ }^{\circledR}$ 150, Combivir ${ }^{\circledR}$, Crixivan ${ }^{\circledR} 400$, Efavirenz, Invirase ${ }^{\circledR}$, Norvir ${ }^{\circledR}$, Rétrovir ${ }^{\circledR} 100$ and 250 , Trizivir ${ }^{\circledR}$, Videx ${ }^{\circledR} 100$ and 200, Viracept ${ }^{\circledR}$, Viramune ${ }^{\circledR}$, Zérit ${ }^{\circledR} 30$ and 40 , Ziagen ${ }^{\circledR}$ ).

Two years of market observation show that sales volumes of antiretroviral drugs are low (less than five boxes per product) and clients infrequent. But, since late 2001, attempts have been made to develop sales: some merchants now clearly identify antiretroviral drugs as 'drugs against AIDS', whereas others are testing the market. In January 2002, one merchant had a stock of 20 boxes of Zerit ${ }^{\circledR} 40$; this clearly required a major investment and suggested that a guarantee of sale had been obtained. Finally, some merchants are specializing in antiretroviral drugs, and are writing (inappropriate) prescriptions themselves, such as monthly or weekly injection of Retrovir ${ }^{\circledR}$, two-drug regimens (zidovudine + didanosine), and Zerit $40{ }^{\circledR}$ monotherapy (touted as being more effective than a three-drug regimen). 
The lot numbers reveal that most of these products come from the northern hemisphere, in the form of donations (by individuals or associations), or health structures supplied by donations, or more elaborate strategies in which drugs are specifically collected in the northern hemisphere for sale in Senegal. Only 13 boxes with lot numbers corresponding to those used in the ISAARV programme have been found, pointing to occasional illicit sale in designated dispensing centers, retrieval of unused drugs after treatment switches, or, more likely, resale by a very small number of patients [18].

Surveys thus confirm that antiretroviral drugs are available on the informal market but suggest that the phenomenon is limited. This is no doubt partly explained by the strict control of drug distribution in the ISAARV programme, and the close follow-up of treated patients.

\section{Discussion}

The strategic choices on which the ISAARV programme was based have been more or less validated in the light of the public health challenges raised by access to antiretroviral drugs in Africa.

The ISAARV programme was set up in a small number of highly competent, specialized sites. The capacities of the health care facilities and the committees managing patient access to ISAARV proved adequate to meet demands, albeit thanks to a pre-selection process that was not initially planned and that, considering access to care, was a failure. Not all patients for whom antiretroviral treatment was medically indicated had access to the programmes, for reasons relating both to AIDS itself (diagnostic errors, difficult access to screening, fear of condemnation, etc.) and available health services in a low-income country (few specialized consultations, high cost of care); the number of medically eligible patients that did not have access to the programme could not be estimated. Social accompaniment ensured through the health care system could not be as sustained as it was planned; it requires the involvement of community-based organizations.

The results of the ISAARV programme show that drug costs alone are not a valid reason for withholding antiretroviral treatment in poor communities. Antiretroviral therapy was funded through specific budgets, thus ensuring [\$100] that resources allocated to other health problems were not 'hijacked'. The spectacular drug price reductions that occurred in 2000 transformed the financial situation. The ISAARV programme facilitated the emergence of an antiretroviral drug market, thus allowing other patients to benefit from the lower cost of treatment.

The risk of accentuating inequalities between rich and poor can currently only be overcome by granting subsidies that cover the entire cost of treatment for a large proportion of the patient population. Indeed, the economic situation in African countries, the impact of AIDS on household budgets, and the cost of treatments other than antiretroviral drugs mean that most patients, despite being able to return to paid employment while on treatment, still cannot pay for their drugs.

Access to strongly subsidized or free treatment permitted providing rational treatment to patients; it also contributed to reducing the demand for antiretroviral drugs on the informal market, and therefore reduced the risk of emergence of viral resistance due to inappropriate use.

\section{Conclusion}

The ISAARV programme demonstrates the feasibility and efficacy of a pilot project of antiretroviral drug access in Africa, with about 400 patients treated in a small number of sites. Senegal's Strategic Plan Against AIDS for 2002-2006 is intended to treat 7000 patients with antiretroviral drugs. Maintaining a high level of care is the main challenge for this programme, as treatment protocols will be managed by less specialized care centers and the programme management will be decentralized. The new sites will be opened gradually, and their performance will be evaluated.

The ISAARV programme has been hailed as a model of AIDS management in Africa [19]. However, this initiative cannot be directly transplanted to other African settings, mainly because part of the information 
infrastructure was set up in a research perspective. This infrastructure must now be adapted to a public health programme.

Finally, the ISAARV programme demonstrates that the social, health and economic situation that prevails in most sub-Saharan countries is not an insurmountable obstacle to the creation of a sound and effective programme of antiretroviral therapy. The need to favor non-discriminatory access to antiretroviral therapies in response to the state of emergency created by AIDS in Africa was underlined at the general assembly of the United Nations on 27 June 2001 [20]. The creation of national antiretroviral programmes is not only the affair of African policy-makers: it must also be based on an international strategic response proportional to the world AIDS crisis.

\section{Acknowledgements}

The authors are grateful to Professor Salif Badiane (deceased), Dr Ngagne Mbaye, the members of the Eligibility Committee, the Medical Committee, the Welfare Committee, and the Drugs and Reagents Management and Supply Committee.

\section{References}

1. Kallings LO, Vella S. Access to HIV/AIDS care and treatment in the South of the world. AIDS 2001; 15: IAS1IAS3.

2. International AIDS Society. Consensus report. Place of antiretroviral drugs in the treatment of HIV-infected people in Africa. AIDS 1999; 13: IAS1-IAS3.

3. Africa. Use of Antiretroviral Drugs in the Management of HIV-infected Persons. Updated Recommendations, October 2000, Paris: ANRS, IMEA, IRD, Société africaine contre le sida, UNAIDS, PNLS-Sénégal, PNLS-Côted'Ivoire, International AIDS Society.

4. de Vincenzi |. How to simplify and adapt antiretroviral combination therapy and monitoring for use in low and middle income countries. Geneva: MSF, 2001.

5. Adams G, Addo M, Aldouini A, Alkfeld M, Anderson D, Carswell KA, et al. Consensus Statement on ART for AIDS in Poor Countries by Individual Members of the Faculty of Harvard University. Harvard: Boston, 2001.

6. WHO. WHO International Consultative Meeting on HIV/AIDS Antiretroviral Therapy. Report of the Meeting. Geneva, 22-23 May 2001. Geneva: WHO: 2001.

7. Desclaux A, Laniéce I, Ndoye I, Taverne B, (eds). L'initiative sénégalaise d'accès aux médicaments antirétroviraux. Analyses économiques, sociales, comportementales et médicales. Paris: ANRS, 2002.

8. Laniéce I, Ciss M, Desclaux A, Diop K, Mbodj F, Ndiaye B, et al. Adherence to HAART and its principal determinants in a cohort of Senegalese adults. AIDS, 2003: 17(suppl 3): S103-S108.

9. Vergne L, Touré Kane C, Laurent C, Diakhaté N, Ngom NF, Gueye M, et al. Low rate of genotypic HIV-1 drugresistant strains in the Senegalese Government Initiative of access to anti-retroviral treatment. AIDS 2002, XXX [ED: this issue]

10. UNAIDS. Acting early to prevent AIDS: The case of Senegal. Best Practices, UNAIDS/99. 34E. Geneva: UNAIDS, 1999.

11. Laurent C, Diakhaté N, Ngom Gueye NF, Toure MA, Sow PS, Faye MA, et al. The Senegalese government's HAART intiative: an 18-month follow-up study of feasibility, effectiveness, adherence, toxicity and viral resistance. AIDS, 2002; 16: 1363-1370.

12. Ciss $M$, Vinard $P$, Diop K. Le système d'approvisionnement et de financement des ARV. In Desclaux A, Lanièce I, Ndoye I, Taverne B (eds): L'Initiative sénégalaise d'accès aux médicaments antirétroviraux. Analyses économiques, sociales, comportementales et médicales. Paris: ANRS, 2002: 67-78. 
13. Canestri A, Taverne B, Thiam S, Laurent C, Ndir A, Schiemann R, Landmann R. Coûts directs du suivi médical à la charge des patients hors antirétroviraux. In Desclaux A, Laniéce |, Ndoye I, Taverne B (eds): L'Initiative sénégalaise d'accès aux médicaments antirétroviraux. Analyses économiques, sociales, comportementales et médicales. Paris: ANRS, 2002: 55-66.

14. Gomes (do Espirito Santo) E. Etude sur l'équité dans l'accès aux soins de santé et les déterminants socioéconomiques des recours aux soins dans la région de Dakar. Dakar: Ministère de la Santé, Fnuap, Service de coopération et d'action culturelle, 2000.

15. Geest (Van der) S, Reynolds-Whyte S (eds). The Context of Medicines in Developing Countries. Studies in Pharmaceutical Anthropology. Dordrecht/Boston/London: Kluwer Academic Publishers, 1998: 392 p.

16. Fassin D. Pouvoir et maladie en Afrique. Paris: PUF, Les Champs de la Santé, 1992: 359 p.

[S101]

17. Werner JF. Marges, sexe et drogues à Dakar. Enquête ethnographique. Paris: Karthala-Orstom, 1993: 292 p.

18. Egrot $M$, Taverne $B$, Ciss $M$, Ndoye I. La circulation des médicaments antirétroviraux au Sénégal. In Desclaux A, Laniéce I, Ndoye I, Taverne B (editors): L'Initiative sénégalaise d'accès aux médicaments antirétroviraux. Analyses économiques, sociales, comportementales et médicales. Paris: ANRS, 2002: 221-231.

19. Health, a key to prosperity. Success stories in developing countries. Senegal contains the spread of HIV. http://vww.who.int/inf-new/aids3.htm

20. United Nations. Resolution adopted by the General Assembly, August 2001. A/RES/S-26/2. New York: UN 2001. 